\title{
JERONIMO COIMBRA BUENO - APONTAMENTOS INICIAIS SOBRE UMA TRAJETÓRIA PROFISSIONAL
}

\author{
Wilton Araujo Medeiros
}

\section{Resumo}

Os aportes iniciais da pesquisa abaixo expostos, abordarão a relação urbanismo/política como um aspecto basilar na trajetória de Jeronimo Coimbra Bueno enquanto urbanista que vai elaborar a cidade, o território e a região, e por fim a si mesmo, num sentido narrativo e até teleológico. Compreende a relação entre urbanismo e política como visada privilegiada de um vasto conjunto de práticas, objetivando a modificação da cidade e do território. Contribui para delinear traços iniciais da trajetória de Bueno, que começou suas atividades como engenheiro e urbanista em Goiânia, chegando a ser governador de Goiás e senador da republica, e, nesse período contribuiu decisivamente para a escolha do local e transferência da Capital da Republica.

\section{Palavras-chave}

Urbanismo, cidade, trajetória profissional.

\begin{abstract}
The initial contributions of the research below exposed, will address the urbanism/policy as a basic aspect in the path of Jeronimo Coimbra Bueno while town planner that will draw up the city, the territory and the region, and finally himself, in a narrative sense and even teleological. Understand the relationship between urbanism and politics as a view privileged of a wide range of practices, aiming at the modification of the city and the territory. Contributes to outline initial traces the trajectory of Bueno, that started its activities as an engineer and urban planner in Goiânia, becoming the Governor of Goiás and Senator of the Republic, and, during this period contributed decisively to the choice of the site and transfer the Capital of the Republic.
\end{abstract}

\section{Keywords}

urban planning, city, career. 


\section{Introdução}

Como mostra Bernardo Secchi em Primeira lição de urbanismo, ao recusarmos a ideia de que práticas são mecânicas aplicações de teorias, podemos ver os vestígios sensíveis do urbanismo, e os discursos que o apoiam, aparecendo em duas camadas, entre as quais se situam os movimentos da sociedade: acontecimentos e processos, nem sempre claros e previsíveis, em uma dimensão opaca que interliga vestígios e processos.

Como poderemos ver nesses apontamentos iniciais de uma trajetória profissional que se moveu no âmbito do urbanismo, não seria possível compreendermos urbanismo meramente como um conjunto de obras, projetos, teorias ou normas associadas a um tema, a uma linguagem e a uma organização discursiva. Muito menos, como um determinado setor de ensino. Mas, ao contrario, como testemunho de um vasto conjunto de práticas, quais sejam, as da continua e consciente modificação do território e da cidade.

Não poderia ser de outro modo, haja vista que a cidade e o território pertencem inevitavelmente a experiência cotidiana de cada um. Portanto, trata-se de uma dimensão opaca porque o urbanismo não está sozinho; este campo está bastante "congestionado", como diz Secchi, porque pensar o urbanismo é de algum modo pensar o mundo. E, "pensar que o mundo possa ser subdividido em tantos compartimentos, cada um sob a alçada de algum estudioso ou especialista, não é um pensamento somente ingênuo, mas é principalmente equivocado" (2006, p. 19).

Não seria possível outro referencial senão este que vê o território, a cidade e a até mesmo o mundo em continua modificação, e que insere o urbanista nesses acontecimentos e processos, para a elaboração de apontamentos iniciais da trajetória profissional de Jeronimo Coimbra Bueno.Pois, como mostra Secchi, o urbanista se move nesse universo complexo, para o qual tem que elaborar figuras que o possibilite um sentido narrativo ou até mesmo teleológico. Elaborar uma ciência, mas também um saber, como um patchwork feito de peças próximas umas às outras e com várias origens históricas, elaborar uma narrativa.

Como veremos a seguir, alguns documentos que nos possibilitam iniciar apontamentos para compreender a trajetória profissional de Jeronimo Coimbra Bueno, foram intencionalmente produzidos por ele para dar esse sentido narrativo à sua prática urbanística. Ainda que seja preciso advertir, nosso personagem em tela movese entre engenharia civil, política e urbanismo, dando relevo a cada uma dessas 
instâncias, conforme o interesse para que seu fim último, a transformação do território e da cidade Ihe seja mais conveniente.

Por isso, é possível pensar que Coimbra Bueno, ao elaborar os seus vestígios, e, articulando-os em processos, pretende fazer do urbanismo o pano de fundo de sua própria história. Por outro lado, é interessante também refletir um pouco também sobre o teor desses vestígios documentais, porque eles frequentemente nos colocam na fronteira entre urbanismo e política, fazendo parecer como indissociáveis. Isso nos faz refletir sobre as praticas urbanísticas ainda hoje.

\section{Intróito sobre política e urbanismo e a um olhar excêntrico a Goiânia}

A lei no 1803 aprovada pelo Congresso em 5 de janeiro de 1953, havia autorizado o Poder Executivo a realizar "estudos definitivos para a localização da nova Capital da Republica". Determinava que "adotasse os limites de 5.000 km² para a constituição do Distrito Federal", base de uma cidade para 500.000 habitantes. Três anos depois, Juscelino Kubitschek iniciaria de fato a construção da nova cidade.

A construção de Brasília e seu complexo sistema de rodovias conectando a capital federal a todo o país, ao mesmo tempo em que corroborará com a tese de que a força do Brasil estava em seu interior, contribuirá para a estigmatização do sertão como um lugar de atraso, e, portanto, deslocado para um lugar mais distante do Planalto Central. Com isso, a construção de Brasília mostra também que a junção entre política e urbanismo foi um dos mais importantes componentes na configuração da nação modernizada.

Essa junção entre política e urbanismo, patenteou-se no Brasil não apenas nas obras de embelezamento urbano levadas a efeito em diversas cidades, sobretudo capitais, desde a segunda metade do século XIX à primeira metade do século XX, com aberturas de avenidas, obras de saneamento, paisagismos, ou transformações de largos religiosos em praças publicas. Uma das mais evidentes provas de que política e urbanismo eram traços definidores da nação em modernização foram as concepções de cidades novas, inúmeras delas localizadas em frentes de colonização, sendo as mais importantes as capitais: Belo Horizonte, Goiânia, Brasília e Palmas.

Outras evidências dessas injunções entre política e urbanismo podem ser vistas nas biografias dos diversos urbanistas atuantes nesse período. Alguns desses urbanistas, como é o caso de Jeronimo Coimbra Bueno, têm suas trajetórias completamente indissociáveis dos cargos políticos que ocuparam. Isso mostra que longe de ser uma ferramenta técnica neutra ou tecnicista, o conhecimento cientifico 
elaborado no âmbito do urbanismo é interdependente dos arranjos políticos, na medida em que suas práticas e discursos os exigem.

Como mostra alguns dados biográficos da trajetória de Coimbra Bueno, não existem práticas urbanísticas sem injunções políticas. Como dizia Pedro Ludovico, político que criou a cidade onde Coimbra Bueno trabalhou logo após ter se formado, nos idos de 1930, o Brasil não podia mais continuar a falar de seu interior de modo romântico, era preciso altas doses de cientificismo para modernizá-lo. Ludovico não somente fundamentou-se teoricamente na lógica de que o urbanismo propiciava ocupação e configuração dos espaços como forma de modernização da nação, mas contratou diversos engenheiros e urbanistas para corroborar os seus intentos políticos. Dentre eles, os irmãos Abelardo e Jeronimo Coimbra Bueno, que trabalharam para os quadros do Governo de Goiás entre os anos de 1934 e 1938, na concepção e efetiva urbanização de Goiânia.

Analisando o relatório de Pedro Ludovico a Getulio Vargas (1930-1933), pude observar a instrumentalização do urbanismo e dos urbanistas na construção da argumentação política para a construção de Goiânia e de sua inserção no concerto da nação. A eficácia de sua argumentação não poderia ser de outra maneira, a não ser por meio de uma argumentação lógica, cientificista, racional, positivista. Para isso, como mostra em suas Memórias publicadas em 1973, seus argumentos políticos foram corroborados em uma instancia urbanística maior, em três aspectos: autoridade; consenso e homologação, presentes nesta citação:

esses três técnicos [Armando Augusto de Godoy/urbanista; Benedito Neto de Velasco/engenheiro civil; Américo de Carvalho Ramos; engenheiro], inegavelmente dotados de larga autoridade no assunto, aplaudiram com entusiasmo, a uma voz, a escolha da comissão, homologando-a sem restrições; (...) mais do que as nossas, valem as palavras dos técnicos (TEIXEIRA, 1973, p. 124).

Em março de 1935, outras "palavras técnicas" dão novos contornos às injunções entre política e urbanismo de Ludovico. Os seus primos Abelardo e Jeronimo Coimbra Bueno, que desde o segundo semestre de 1934 trabalhavam na direção do Serviço de Viação e Obras Publicas de Goiás, o enviaram uma carta tecendo severas criticas ao plano urbanístico de Correia Lima. Trechos dessa carta estão registrados em A luta na epopeia de Goiânia: uma obra da engenharia nacional, livro que circulou apocrifamente $^{1}$ no período da inauguração oficial de Goiânia, em 1942.

\footnotetext{
${ }^{1}$ Segundo ACKEL (1986, p. 180) Correia Lima recorreu a instâncias judiciais para provar que o projeto urbanístico de Goiânia era de sua autoria, e saiu-se vitorioso. No ano de 1942, durante a inauguração oficial de Goiânia, Correia Lima foi homenageado como o urbanista de Goiânia. Esse alijamento 
Disseram os irmãos Coimbra Bueno a seu primo Ludovico:

É quase impossível a um só técnico por mais criterioso que seja, ou por mais cuidado que tenha, atender a todas as múltiplas questões que se Ihe apresentam e a infinidade de detalhes que Ihe reclamam a atenção, sem correr grande risco de deixar falhas. (...) Assim foi feito o estudo da cidade de Bello Horizonte e, mais recentemente, o plano do urbanista Agache, para a remodelação da cidade do Rio de Janeiro foi submetido ao estudo de uma comissão especialmente creada [sic] para esse fim, e, ainda no ano passado, debatido o plano do aero-porto do Rio de Janeiro, isto só para citar alguns exemplos brasileiros (ALVARES, 1942, p. 12).

Mais adiante, na página 13, Álvares diz que os irmãos Coimbra Bueno sugeriram ao Interventor os nomes dos seguintes engenheiros: Domingos da Silva Cunha; Armando Godói; Anhaia Melo; Jorge Leuzinger; Affonso Reidy; Armando Novaes e mais um engenheiro a ser indicado pelo Clube de Engenharia". Além dessas "palavras técnicas", Álvares diz ainda que nesta carta os irmãos Coimbra Bueno sugerem a Ludovico o máximo de publicidade em torno das novas configurações urbanísticas - "nos pomos à disposição de V.Excia. para cumprirmos esta parte" (idem).

A publicidade se destacou como política empreendida pelo Estado Novo. Os argumentos dos engenheiros Coimbra Bueno podem ser perfeitamente compreendidos como fazendo parte desse contexto histórico. Aliás, essa questão da inter-relação entre publicidade e construção de cidade já havia sido abordada por Armando Godói no parecer que apresentou a Pedro Ludovico em 1933 - "uma propaganda bem dirigida no sentido de atrair capitais e habitantes. Temos a respeito um exemplo bem eloqüente na construção de Magnitorsk" (apud MONTEIRO, 1938, p. 58).

Essas sugestões de cunho técnico, inclusive a ligação entre urbanismo e publicidade apreendida do mestre Armando Godoy, vieram a lume após cinco meses de reestudo do projeto urbanístico de Correia Lima, desde que a firma Coimbra Bueno e Pena Chaves assumiram a Superintendência de Obras, em novembro de 1934. A par do esforço empreendido pelos engenheiros para associar urbanismo com os aspectos construtivos da cidade em urbanização como bem mostra Silva (2003, p. 132), é interessante observar que, sem descurar da engenharia como construção, passam a efetuar a construção da cidade nas injunções entre urbanismo e política.

intencional dos Coimbra Bueno fez que os engenheiros construtores de Goiânia reagissem com a publicação e circulação apócrifa durante o evento.

URBANA, V.5, n 7, out.2013 - Dossiê: Urbanistas e Urbanismo: a escrita da história... - CIEC/UNICAMP 
Essas injunções da construção da cidade entre urbanismo e política, surtiu efeito: no mesmo mês em que os engenheiros Coimbra Bueno assinavam o contrato para construir os Correios, em abril de 1935, Correia Lima rescindia o seu (MONTEIRO, 1938, pgs. 133; 148; 154-155).

Podemos admitir que tivesse sido o próprio Pedro Ludovico o responsável pela iniciação de seus primos Abelardo e Jerônimo Coimbra Bueno nas práticas políticourbanisticas, já que, recentemente formados em 1934, foram por ele contratados para liderarem a construção da nova capital goiana, em substituição ao renomado Attílio Correia Lima.

Porém, observando a perspicácia dos Coimbra Bueno para seguirem a trilha do urbanismo a partir de sua inserção prática costurada em tecitura política, deixam evidente que urbanismo e política são profundamente articulados entre si, sendo que a trajetória profissional evidencia bastante isso. Tanto é assim que, no dizer de Silva (1997, p. 39), foi Jeronimo Coimbra Bueno quem construiu politicamente Brasília, ao conseguir a adesão do candidato, depois presidente da republica. De fato, Bueno diz em depoimento que Juscelino Kubitschek o solicitara um plano urbanístico para Belo Horizonte, e outro para Brasília, tendo se recusado a fazê-los nas duas ocasiões, dando vez a Niemeyer com a proposta da Pampulha e ao concurso para Brasília, do qual Lucio Costa saiu-se vencedor ${ }^{2}$.Tendo mesmo, sido um sustentáculo político de Kubitschek atuando no congresso como Senador (1954-1962).

Bueno, atuando em diversas Comissões do Governo Federal pró-interiorização da Capital Federal entre 1946 e 1961, dava continuidade e reforçava a presença atuante dos goianos neste processo, desde a Comissão Cruls em fins do século XIX. Porém, como veremos a seguir, a sua inserção política nas teias que os goianos teceram a fim de que os intentos republicanos sobre a mudança da capital ao interior do Brasil fossem levados a efeito, aperfeiçoou seu olhar excêntrico à Goiânia, mesmo no período em que foi governador de Goiás.

\section{Excêntrico a Goiânia: em torno de justificativas governamentais}

Durante o período em que foi governador de Goiás, Coimbra Bueno participou, concomitantemente, como membro da Comissão especial de mudança da Capital da Republica (1946-1948), da qual participava desde outubro de 1946, dois meses depois de promulgada a Constituição que ratificava a transferência da capital da

\footnotetext{
${ }^{2}$ Cfe. Depoimentos de Abelardo e Jeronimo Coimbra Bueno - Programa de História Oral. Brasília, Arquivo Publico do Distrito Federal, Páginas 22 e 35. 
republica para o Planalto Central, como já estabelecia as constituições de 1891 e 1934

Cumprindo essas duas funções públicas ao mesmo tempo, o então Governador teve a oportunidade de colocar em prática o "neo-bandeirismo" que propôs quando lançou a Cruzada Rumo ao Oeste - ver Figura 1, abaixo.

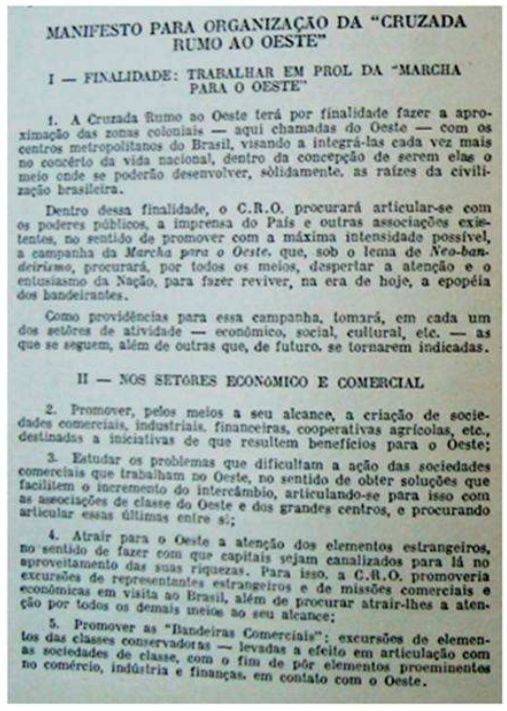

Figura 1: Páginas 1 a 3 do Manifesto para organização da "Cruzada rumo ao Oeste", compilado por Coimbra Bueno.

Fonte: BUENO, 1961.

Com isso, o governador que entre 1935 e 1938 havia sido engenheiro construtor da nova capital de Goiás dava mostras de que a sua atuação em Goiânia era muito mais parte da sua militância pró-interiorização do Brasil do que especificamente a urbanização ou preocupações com o urbanismo da capital, como seria esperado, já que à época era atribuição do governo estadual.

O pleito eleitoral para o governo estadual ocorreu em janeiro de 1947, e Coimbra Bueno tomou posse como Governador em março de 1947. Como o anterior governante de Goiás administrara pessoalmente a Capital durante doze anos, entre 1933 e 1945, havia a expectativa que o próximo teria dedicação semelhante, contribuindo para isso também o fato de que à municipalidade resultava um papel coadjuvante e mimetizado como um elemento do governo estadual.

As viagens freqüentesao rio de Janeiro ocorreram até agosto de 1948, tendo Coimbra Bueno participação decisiva para que a capital fosse localizada dentro do que posteriormente ficou conhecido como "quadrilátero Cruls". Nesse período, a comissão reuniu-se 23 vezes, 22 vezes no Rio de Janeiro e uma na Chapada dos 
Veadeiros.Bueno, porém, não se continha apenas nos trabalhos de estudos para a localização da nova Capital Federal. Demonstrava também o "neo-bandeirismo" colocando o Governo de Goiás a serviço de seus ideais e convicções.

Para Bueno, a interiorização da Capital Federal seria o "denominador comum" de todos os problemas, porém, não problemas de Goiás ou de Goiânia, mas o problemas referentes à construção da nação, ou à "salvação nacional":

Desejamos, nesta oportunidade, pedir a atenção dos homens públicos para os nossos grandes problemas, já equacionados ou em execução. (...) Todos os esforços conjugados do Estado e da União, deverão ser sempre norteados pelo denominador comum - da interiorização da Capital Federal, obra inadiável de salvação nacional (Diário Oficial: 15/07/1950).

Está claro, nessa citação, que Coimbra Bueno não se refere à urbanização de Goiânia como um "grande problema" a ser resolvido enquanto era governador de Goiás. Com isso, fica claro, também, que essa é a voz do "sonhador" e não do engenheiro que construiu Goiânia ${ }^{3}$. A obra a qual se refere não é de um plano de urbanização, mas de um plano de "salvação nacional".

Tanto as prolongadas ausências do governador no Palácio das Esmeraldas, quanto a visível dedicação à causa federal, fez recrudescer a oposição do PSD de Goiás, multiplicar as críticas dos populares, e ferrenhas dissidências de companheiros de partido.

Essa ausência de Bueno em Goiânia, inicialmente por causa de sua participação na referida comissão, em seguida, devido aos projetos de imigração e de estudos regionais que também elaborou junto ao Governo Federal, gerou uma arena política que deslocou em grande medida, o interesse pela continuidade de planificação de Goiânia para o interior do Estado, para a região do Brasil Central e para o território nacional. Os principais pontos do programa de governo de Coimbra Bueno eram excêntricos a Goiânia.

Ora, os habitantes de Goiânia, acostumados a vê-locerca de uma década antes como engenheiro construtor da cidade, possivelmente, questionavam-se porque, ao invés de continuar as práticas urbanísticas, estava bem mais preocupado com os "grandes problemas", com a "interiorização da Capital Federal" e, até mesmo, com a "salvação nacional". No entanto, Coimbra Bueno dizia, em sua defesa:

\footnotetext{
${ }^{3}$ Para Silva (1997, p. 41), mapeando tipologias weberainas, isso configuraria exemplaridade do tipo social "sonhador" - aquele que estimula perpetuamente a chama da própria convicção. 
O que fizemos, o que pudemos realizar, não é segredo, nem difícil de ser apreendido, salvo pelos que não querem ver, pelos derrotistas e negadores sistemáticos do esforço, proficiência e realizações de outrem.

O povo, (...) temos certeza de que compreendeu e reconhece o que realizamos; e isto é bastante, - é tudo (idem).

Esse discurso em sua defesa foi feito na Assembléia Legislativa do Estado de Goiás, em junho de 1950, dias antes de sua renuncia e passagem do cargo para o vice-governador. Para Bueno, os políticos goianos, inclusos alguns colegas de partido, não tinham o esclarecimento necessário para compreenderem sequer o que havia sido proposto em seu programa de governo, que apresentou ao tomar posse em 1947. Por isso, justifica, foram esses "menos esclarecidos" os responsáveis pelos seus insucessos na gerencia do Estado de Goiás, que o levou a renunciar ao governo.

O programa de governo que delineamos em princípios de 1947 sofreu a imediata e forte oposição, que sempre encontramos por parte de grupos menos esclarecidos, empenhados em provocarem, para futuros proveitos pessoais, o insucesso de nossa atuação na gerência dos negócios públicos (Ibid.).

Como se vê, Bueno encontra na suposta obscuridade da oposição política, a maior justificativa para renunciar às tarefas que the cabiam como líder do poder executivo do Estado.

Ao invés de encontrarmos por parte de alguns que nos são contrários uma ação fiscalizadora, vigilante e eficiente, fomos alvo de uma oposição que desde o primeiro dia de nosso Governo se avocou a função de criar embaraços, sabotando conscientemente ou não as iniciativas governamentais e combatendo sistematicamente qualquer medida que se adote ou se ponha em prática (Ibid.).

As iniciativas governamentais, a que se refere Bueno, eram projetos realizados em parceria como governo federal visando à interiorização da Capital Federal. Em momento algum nesse discurso que antecede a renuncia, Bueno faz referencias diretas às divergências política entre ele e seu primo Pedro Ludovico, quem o contratou em 1934 para dirigir a construção de Goiânia. 
É possível supor que, as primeiras causas dessa oposição política estejam no modo como Bueno, aproveitando-se da sua condição de engenheiro responsável pela construção de Goiânia, fez incluir parte das terras que havia recebido como pagamento por seu trabalho, no Plano de Urbanização, com o nome de "Cidade satélite Campinas". Aliás, grande parte da historiografia goiana tende a minimizar o trabalho de Coimbra Bueno em Goiânia, preferindo associá-lo, por isso, aos "gananciosos imobiliários" como podemos ver em Maciel (1996, p. 161); Unes (2001, pp. 68-69); Ribeiro (2004); et all.

A meu ver, não é possível desconsiderar a boutade imobiliária e suas consequências, na trajetória de Coimbra Bueno. Porém, considerá-la tão somente como viés de causa-efeito torna-se redutor, não apenas para compreender a trajetória profissional de Bueno, como o próprio processo de produção do espaço urbano de Goiânia, que extrapola em muito a simples análise de formação e deformação do sistema fundiário pelo Estado.

A questão central, a qual energiza ambas as coisas, é que, ao longo do processo de interiorização da Capital Federal desde o início do século XIX como mostra Vidal (2009, p. 37), processo esse intensificado após o advento da República,concomitantemente políticos e intelectuais goianos apropriaram-se da posição que Quadrilátero Cruls ocuparia, ou seja, dentro do Estado de Goiás. Além disso, como ainda havia muita indefinição a respeito do local exato onde seria edificada a nova cidade, os goianos aventavam a possiblidade de Goiânia vir a ser a capital do Brasil, do mesmo modo que os mineiros propunham que fosse Belo Horizonte.

Coimbra Bueno insere-se nesse contexto, porém a sua atuação desenvolveu-se de maneira excêntrica à capital de Goiás, e, ainda mais importante para os delineamentos de sua trajetória profissional, praticamente oposta ao modo como os goianos concebiam a relação dualista sertão/litoral. Essas questões nos levam a procurar compreender o olhar excêntrico de Coimbra Bueno em relação a Goiânia, no período em que foi Governador de Goiás.

Para isso, em seguida, é necessário compreender alguns elementos que configuravam o locus de atuação dos intelectuais e políticos goianos no Rio de Janeiro, em particular o "espírito geográfico" formatado pela escrita da revista A informação goyana, e como esse locusde atuação posiciona Goiás econômica e politicamente na hinterlândia.

\section{Um primeiro contexto: 0 "espírito geográfico" dos goianos}


Souza (1997, p. 112) mostra que a formulação do "espírito geográfico", ou seja, a arrancada em direção ao interior do Brasil para construir uma nova totalidade nacional não é exclusividade do período estado-novista. Desde que a Missão Cruls demarcou o centro geométrico do Brasil- dentro do Estado de Goiás -, passando-se a figurar em todos os mapas do Brasil o quadrilátero onde deveria estar situado o Distrito Federal, que os políticos goianos se esforçaram para concretizar a interiorização da Capital Federal.

Nepomucemo (2003) referencia seus estudos em Souza (1997), em boa medida para mostrar como a revista A Informação Goyana (ver Figura 1) delineou a formação de certa consciência sobre Goiás no período em que a revista circulou, ou seja, entre 1917 e 1935. O grupo de intelectuais goianos, do qual alguns moravam no Rio de Janeiro, outros em Goiás, reuniu-se em torno desse "espírito" de que à Nação, mais do que ao Estado, pressupunha-se a conquista da hinterlândia. Não por acaso, veio de um dos principais representantes desse grupo de intelectuais, Americano do Brasil, a proposta de marco comemorativo do centenário da Independência no Planalto Central: a pedra fundamental da futura construção de Brasília.
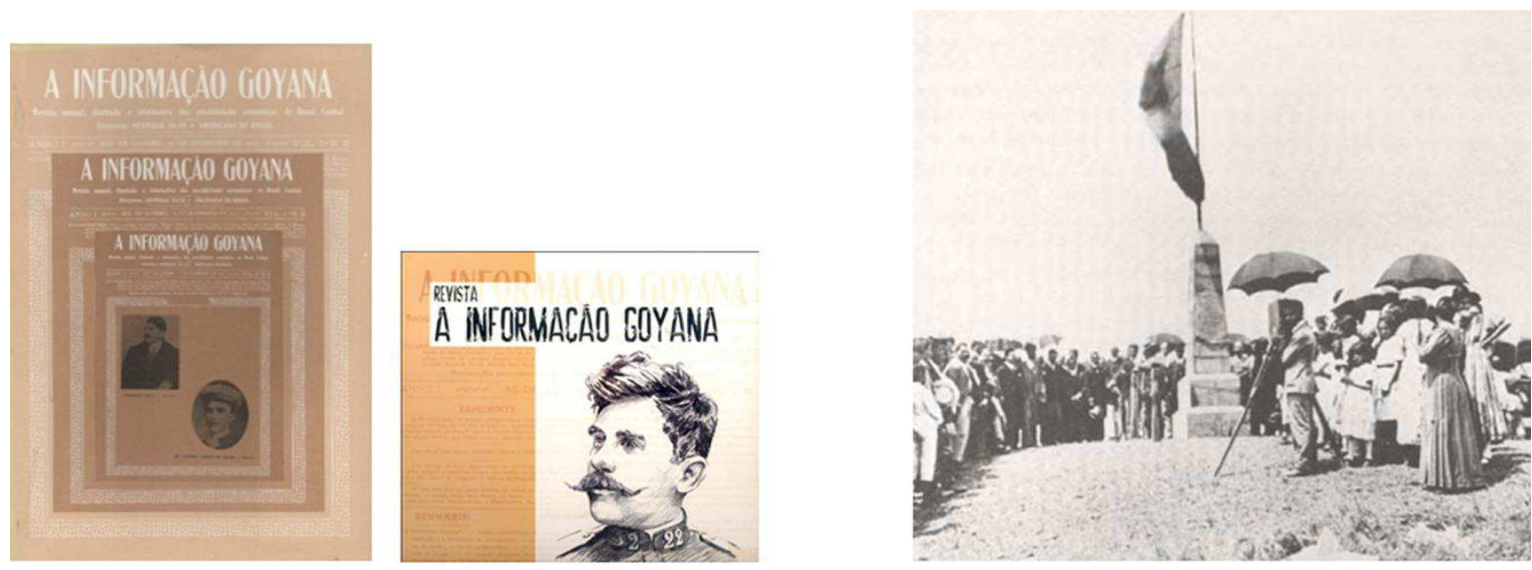

Figuras 2 - Duas edições fac-simile da Revista $A$ informação goyana, publicadas pelo Governo do Estado de Goiás (Fonte: arquivos do autor).

Figura 3 - Foto do obelisco e pedra fundamental da futura capital federal, em Planaltina.

(Fonte: VASCONCELOS, 1978, p. 238).

A Informação Goyana abrangia um grande leque de colaboradores. Para compor o seu conteúdo, colaboradores, dos mais diversos campos do conhecimento como médicos, sanitaristas, historiadores, geógrafos, advogados, professores, escritores, poetas, religiosos, políticos e, principalmente, engenheiros e militares, na sua maioria 
goianos. Assim como Henrique Silva, Pedro Ludovico e muitos outros goianos que se formaram no Rio de Janeiro, Jeronimo Coimbra Bueno também estava imbuído desse "espírito geográfico". Com isso, propunham apresentar as riquezas do Brasil Central, divulgando que a partir de Goiás cumpria-se "um expressivo papel no futuro da nacionalidade brasileira, não pela excelência e diversidade de seus atributos naturais, mas, ainda, por sua privilegiada localização" (NEPOMUCEMO, 2003, p. 145).

Porém, a grande diferença de Coimbra Bueno para os demais goianos, é que propunha uma interiorização no sentido do litoral para o interior, e não no sentido do interior para o litoral, como propunham os políticos goianos. Por causa disso, sobretudo após o período em que atuou como Governador de Goiás, Coimbra Bueno passará a ser visto pelos seus opositores como um político por fora da realidade goiana, reforçando, deste ângulo, os atributos do "sonhador".

Embora tenha partilhado de algumas similaridades comuns aos políticos e intelectuais goianos, Coimbra Bueno formula o "espírito geográfico" de modo dessemelhante à maioria dos goianos atuantes nas mais diversas áreas. Porém, ainda que partilhasse do mesmo contexto intelectual na base de sua formação com outros goianos, a sua trajetória vai ser diferenciada, pelo fato de ter aliado engenharia e política, diferentemente de Americano do Brasil e Pedro Ludovico que aliavam medicina à política, e da grande maioria do staff governamental e politico que associavam judicilização e política.

A seguir, algumas observações de dados e situações vividas por Coimbra bueno, que talvez possibilitem uma tessitura entre engenharia, urbanismo e política, elementos que possivelmente contribuam para a compreensão de sua trajetória profissional

\section{Compreendendo o sonho de Jeronymo Coimbra Bueno pela interiorização da Capital Federal}

A fim de compreendermos a inflexível postura do "sonhador" pela interiorização da Capital Federal, devemos lembrar que, assim que os engenheirosAbelardo e Jeronimo Coimbra Bueno deixam de administrar a urbanização de Goiânia, em maio de 1939, enviam uma carta ${ }^{4}$ ao Presidente Vargas, declarando a sua fé e entusiasmo pela interiorização da Capital Federal. Em um trecho da carta, dizem o seguinte:

\footnotetext{
${ }^{4}$ Súmula da carta enviada a Getulio Vargas, In Bueno (1961).

URBANA, V.5, n 7, out.2013 - Dossiê: Urbanistas e Urbanismo: a escrita da história... - CIEC/UNICAMP
} 
Antecipamos, Senhor Presidente, a nossa fé e o nosso entusiasmo pelos benefícios que advirão à nossa Pátria (da interiorização da Capital Federal) - se, ao invés de cristalizar o assunto em dispositivos constitucionais, como o fizeram nossos dirigentes de antanho, Vossa Excelência houver por bem lançá-lo no tabuleiro das realizações (BUENO, 1961, p.6).

Conforme expõem Jeronimo e Abelardo Coimbra Bueno, que assinam a carta, a fé e o entusiasmo se davam pelo menos por duas razões: em primeiro lugar, eles mesmos poderiam iniciar tal empreitada, já que, com o sucesso obtido na construção de Goiânia, tinham adquirido suficiente "experiência, tirocínio e capacidade de trabalho". Em segundo lugar, juntamente com Goiânia, Belo Horizonte também era uma demonstração inequívoca de que progresso é decorrente do processo de urbanização.

Mas não só isso. Quando os irmãos Coimbra Bueno enviam a referida carta a Vargas, a política de interiorização Marcha para o Oeste, já haviasido oficialmente lançada há um ano e cinco meses, em 31 de dezembro de 1937. Nesse ínterim, e provavelmente por terem conhecimento e envolvimento com a política oficial de interiorização os irmãos Coimbra Bueno fundaram o Jornal Rumo ao Oeste, e, um ano após, quando da estada de Vargas em Goiânia em 1940 para a inauguração da Marcha para o Oeste, fundam a sociedade denominada Cruzada rumo ao Oeste, e, no inicio do ano seguinte, juntamente com onze editores, fundam o Editora Rumo ao Oeste $^{5}$. Importante enfatizar, Abelardo e Jerônimo Coimbra Bueno estavam presentes na inauguração da Marcha para o Oeste em Goiânia, Ocorrida no Automóvel Club, ocasião em que foi lido o Manifesto para organização da "Cruzada rumo ao Oeste" (Cfe. Figura 1): "A 'Cruzada Rumo a Oeste' é merecedora de nosso apoio e do nosso aplauso, porque pretende, pela propaganda, desenvolver o pensamento e a ação em torno desse tema que é um roteiro da nossa civilização". (apud BUENO, 1961, p. 9).

Observando o que os irmãos Coimbra Bueno tinham dito na Carta enviada a Vargas e as pretensões declaradas da Cruzada Rumo ao Oeste, é possível perceber semelhanças entre o empreendimento do "roteiro de nossa civilização" e a construção

5 "O titulo do Jornal "Rumo ao Oeste", registado [sic] e matriculado no Registo [sic] de Tiulos e Documentos - Cartório do Dr. José Soares de Arruda em São Paulo, em 22 de setembo de 1938". In Diário Oficial (Secção I); Abril de 1941 - http://www.jusbrasil.com.br/diarios/2242765/dou-secao-1-1504-1941-pg-58/pdf. "Todos os subscritores das ações da Sociedade Anônima a se constituir sob a denominação de Editorial Rumo ao Oeste S.A., a saber: Dr. Jerônimo Coimbra Bueno, Dr. Abelardo Coimbra Bueno, Dr. Paulo Paulista de Ulhôa Cintra, Dr. Francisco de Paula Marques Lopes, Dr. Cássio Veiga de Sá, Dr. Salvador Duque Estrada Batalha, D. Ambrosina Parassú Borges Coimbra Bueno, D. Sofia Martins de Ulhôa Cintra, Nivaldo C. de Ulhoa Cintra, José Seixal Filho, Golfredo Francisco Cumán". (idem). 
de Goiânia. Inicialmente, os engenheiros oferecem os seus serviços a Vargas, amplamente respaldados na experiência profissional que obtiveram no período em que trabalharam em Goiânia,posteriormente, oferecem a propaganda e o "neobandeirismo":

O C.R.O. procurará articular-se com os poderes públicos, a imprensa do País e outras associações existentes, no sentido de promover com a máxima intensidade possível, a campanha da Marcha para o Oeste, que, sob o lema de Neo-bandeirismo, procurará, por todos os meios, despertar a atenção e o entusiasmo da Nação, para fazer reviver, na era de hoje, a epopéia dos bandeirantes (BUENO, 1961, p. 10).

Como se vê, os fios da trama politica que Coimbra Bueno vai tecer são compostos pelos poder publico, a imprensa e as associações em voga á época, visando promover a Marcha para o Oeste, e, com isso formular a construção da Nação, em processo no período. Sob esta roupagem de "ideólogo" do Estado Novo, de certo modo assemelhando-se ao papel assumido por Cassiano Ricardo nos anos de 1930 e $1940^{6}$, Bueno vai deixar em segundo plano, pelo menos em Goiás, a identidade de engenheiro construtor, para assumir uma postura mais intelectual.

Porém, a meu ver, o outro fio que o engenheiro articula a sua trama política é com a própria engenharia, configurando por meio desta, uma espécie de urbanismo de constituição do território, e não especificamente da cidade. É essa sua preocupação "urbanística" na configuração do território que, a meu ver, explica o seu governo excêntrico à cidade de Goiânia, e focalizado no interior do estado de Goiás.

Durante seu governo em Goiás, Coimbra Bueno levou a efeito diversas expedições de estudo na região do Brasil Central.Como resultado desses estudos exploratórios sobre a região, seu governo publicou uma série de Boletins, editadapela Imprensa Oficial do Estado - ver Figura 4. Sendo que, o próprio Bueno publicou o texto "Rio Tocantins - 'o Mississipi da América do Sul"no livro organizado por Manoel Demosthenes e publicado no Rio de Janeiro pela Livraria Agir Editora em 1947, como o primeiro volume da série - ver Figura 5.

\footnotetext{
${ }^{6}$ O Bandeirismo,liderado por Cassiano Ricardo, tem origem no Movimento Verde e Amarelo, Grupo composto pelos paulistas Plínio Salgado, Cassiano Ricardo, Menotti del Picchia, Cândido Mota Filho e Alfredo Élis, a vertente conservadora do movimento modernista, a qual na década de 1930 bifurcou-se em integralismo e bandeirismo, este último liderado por Cassiano Ricardoe o integralismo por Plínio Salgado. Coerente com a defesa de que os bandeiristas deveriam fortalecer o Estado, ao longo da década de 1940, Cassiano Ricardo, Menotti del Picchia e Candido Mota Filho iriam tornar-se, em diferentes graus, ideólogos do Estado Novo.
}

URBANA, V.5, n 7, out.2013 - Dossiê: Urbanistas e Urbanismo: a escrita da história... - CIEC/UNICAMP 
Então, compreender essa trajetória intelectual que forja a essência da sua trajetória política, é também compreender o deslocamento que produz uma "identidade contrastiva" no delineamento de sua trajetória profissional.Talvez com isso, a trajetória de Bueno esteja nos dizendo que a identidade do profissional pode ser mais bem iluminada à luz das tramas de sua biografia. "Neste caso, não se trata de identidade do self, definida em termos culturais, mas de papel que ocupa, pelas relações que estabelece no grupo em função das expectativas de comportamento associadas às posições que as pessoas ocupam nele" (SARBIN, 1986 apud PAIVA, 2007, p. 78).

Segundo Gomes (2004, p. 80) as trajetórias de indivíduos e grupos caracterizam esforços de reunião e de demarcação de identidades, associando-se a determinados momentos e eventos às características-projetos de sua produção intelectual. Daí a ênfase na abordagem tanto do objeto quanto da fonte, a partir de trabalho com periódicos, casas editoras, associações culturais, enfim, publicações referentes de lugares de sociabilidade, "onde os intelectuais se organizariam, mais ou menos formalmente, para construir e divulgar suas propostas".

Portanto, Coimbra Bueno talhará traços para os biógrafos de sua trajetória profissional como de homem público, por ter especialmente voltado para a configuração de um "sujeito incomum", na medida em que se apresenta ao publico por identidades contrastivas, mas também ao passo em que desloca o seu olhar para a região, e não para o Estado que então governava. E isso pode ser constatado a partir da análise dos documentos (públicos) nos quais intencionalmente registrou os seus feitos.

$\mathrm{Na}$ realidade, esse distanciamento entre a identidade do engenheiro construtor comum, e a tecitura de elementos para uma biografia de sujeito publico incomum, é fundamental para que entendamos a enorme distância entre o que Coimbra Bueno propunha em seu plano de Governo e a continuidade administrativa e urbanizadora que os goianienses esperavam dele.

Dando prioridade à política em âmbito federal, alinha-se às políticas de colonização: "Para isso, a C.R.O. promoveria excursões de representantes estrangeiros e de missões comerciais e econômicas em visita ao Brasil, além de procurar atrair-lhes a atenção por todos os demais meios ao seu alcance" (BUENO, 1961, s/p.).Interessante perceber que essa canalização de recursos e mão de obra estrangeira deveria ocorrer no Oeste, ou seja, numa "região". Isso mostra que os seus interlocutores são os brasileiros, e não os goianos. 
Conforme Bueno, a finalidade número um da Cruzada era: "desenvolver, solidamente, as raízes da civilização brasileira" (BUENO, 1961, p. 8), aproximando o Oeste dos centros metropolitanos. Isso Bueno procura equacionar em seu governo com a proposta de abertura de "grandes vias de acesso" que seriam as precursoras da interiorização da Capital Federal:

As "grandes vias" de acesso e penetração, serão as precursoras da maior obra da nacionalidade em todos os tempos: - a interiorização de sua Capital. E foi por isto que nos deslocamos da área palaciana de Goiânia, para os distantes rincões de nosso Estado, e para a Capital Federal, onde passamos boa parte de nosso tempo e lutamos com uma equipe de bons brasileiros, (...) não ao regionalismo acanhado de um Estado pobre, mas ao cumprimento essencial e preliminar do Artigo $4^{\circ}$ da Constituição Federal que está sendo realizado, isto é - preparo e desenvolvimento preliminar do Planalto Central - para tornar-se sede da administração Federal (Diário Oficial, 15/07/1950).

Como se vê, Coimbra Bueno novamente deixa bastante claro a instrumentalização de seu governo para a interiorização da Capital Federal. Interessante perceber, que, quando fala nas vias de penetração, dá a elas o significado de serem precursora da "maior nacionalidade de todos os tempos", o que deixava patente que seu regionalismo não era acanhado, como talvez fosse o de alguns correligionários seus e adversários políticos. 

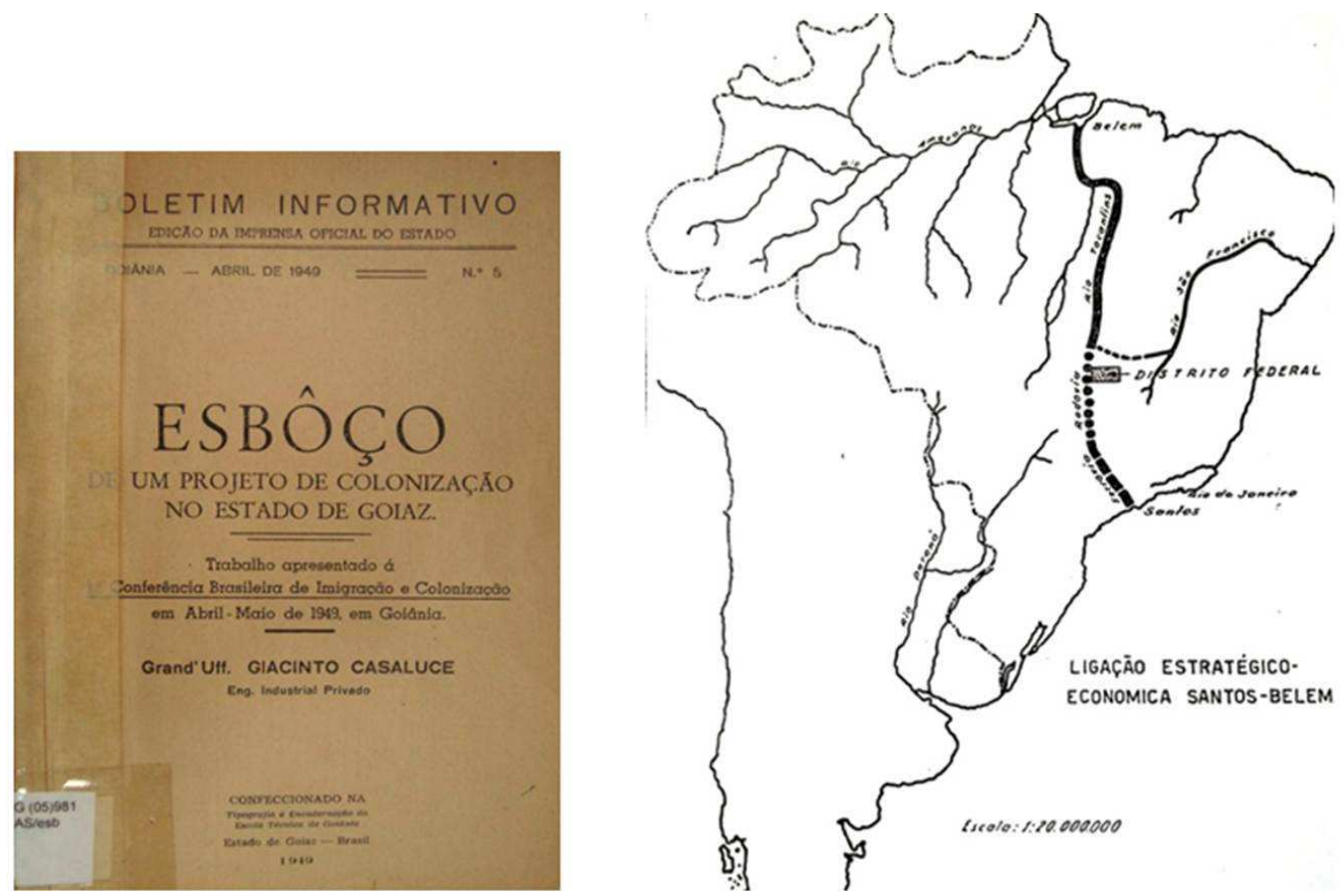

Figura 4: Boletim Informativo no 5.

Fonte: Academia Goiana de Letras/ Casa Altamiro de Moura Pacheco.

Figura 5: ilustração do texto Rio Tocantins - 'o Mississipi da América do Sul, em que Coimbra Bueno, dentre outras coisas, propõe a interligação entre Belém Norte, sul e Nordeste, por meio de rodovia, ferrovia e hidrovia.

Fonte: DEMOSTHENES, 1947, p.63,

\section{Considerações}

A arena política que se formou em oposição ao urbanista que governou o Estado de Goiás entre 1947 e 1950, na prática, contribuiu ainda mais para a consolidação do escritório de Coimbra Bueno no meio urbanístico. Na verdade, sua a aceitação nos meios políticos já era muito grande, como pôde ser visto com a concepção e implantação do plano urbanístico para Curitiba em 1942, conhecido como "Plano Agache".

As injunções políticas de Bueno mostram que essa urbanística por ele praticada deriva da ideia de "um saber que se move em um setor muito aberto" (SECCHI, 2006, p. 49). Do qual, cada elemento e o conjunto inteiro adquirem sentido para nós quando relacionados reciprocamente sobre um plano contextual, se entrevistos ao longo daquilo que poderemos indicar como os eixos do olhar, do desejo e do discurso.

Para Secchi, isso é um tanto quanto "evasivo", mas, ao analisar a história do urbanismo e dos urbanistas no decorrer do século $\mathrm{XX}$, observa que quase sempre aceleram a "morte do autor". É isto que está implícito nestes apontamentos iniciais parauma trajetória profissional de Jeronimo Coimbra Bueno. Mas, que poderá ser 
explicitado cada vez mais, tanto em análises de detalhes quanto de contextos, à medida que a pesquisa nos documentos por ele deixados avance.

Contudo, de um modo geral é possível percebermos que, até 1963, ano em que Coimbra Bueno aposentou como senador, as relações entre urbanismo e política foram preponderantes para delinearmos a sua trajetória profissional. Bueno veio a falecer em 1993. Os trinta anos seguintes após Bueno ter alcançado os seus propósitos político-urbanísticos são obscuros tanto na literatura sobre urbanismo quanto em geral. E é preciso melhor investigar, seja para corroborar, seja para questionar esses apontamentos iniciais e as considerações aqui registradas.

Porém, considerando esses apontamentos iniciais como válidos, podemos pensar como Secchi. Que, para poder ser convincente e aceito, o urbanista é impelido a dispor, em cada instância, de argumentos dotados de suficiente prestígio: seja para fazer valer a autoridade da não contradição factual e lógica, seja para fazer valer a autoridade da lei; mas também para dotar esses argumentos com a autoridade da imaginação, da retórica e do mito.

\section{Referências}

ABREU, Regina (1996). A fabricação do imortal: memória, história e estratégias de consagração no Brasil. Rio de Janeiro: Rocco; Lapa.

A INFORMAÇÃO GOYANA (1917-1935). Edição fac-símile. Goiânia: Agepel, 2001 (Cdroom).

ACKEL, Luiz Gonzaga (1986). Attílio Correa Lima: um urbanista brasileiro. Dissertação (Mestrado). São Paulo: Universidade Mackenzie.

ÁLVARES, Geraldo Teixeira (1942). A luta na epopéia de Goiânia: uma obra da engenharia. Rio de Janeiro: Of. Graf. do Jornal do Brasil.

BUENO, Jerônymo, Coimbra. Rio Tocantis - "o Mississipi da América do Sul". In DEMOSTHENES, M. (Org.) 1947. Estudos sobre a nova capital do Brasil. Rio de Janeiro: Livraria Agir Editora.

DEMOSTHENES, Manoel (Org.) 1947. Estudos sobre a nova capital do Brasil. Rio de Janeiro: Livraria Agir Editora.

MACIEL, Dulce Portilho (1996). Goiânia / 1933-1963. Estado e capital na produção da cidade. Doutorado em história Moderna e Contemporânea. Niterói:UFF. NEPOMUCEMO, Maria de Araújo(2003). O papel político-educativo de A informação Goyana na construção da nacionalidade. Goiânia: Editora de UFG. 
PAIVA, Geraldo José de (2007). Identidade psicossocial e pessoal como questão contemporânea. In: PSICO - Porto Alegre, PUCRS, v. 38, n. 1, pp. 77-84, jan./abr. ; RIBEIRO, Maria Eliana Jubé (2004). Goiânia: os planos, a cidade e o sistema de áreas verdes. Goiânia: Ed. Da UCG.

SARBIN, Theodore R. (Org.) (1986). The storied nature of human conduct. New York: Praeger.

SECCHI, Bernardo (2006). Primeira lição de urbanismo. São Paulo: Perspectiva. SILVA, Luís Sérgio Duarte da (1997). A construção de Brasília: modernidade e periferia. Goiânia: UFG.

SILVA, Lucia (2003). História do urbanismo no Rio de Janeiro: administração municipal, engenharia e arquitetura dos anos 1920 a Ditadura Vargas. Rio de Janeiro: e-Papers.

SOUZA, Candice Vidal e (1997). A Pátria Geográfica. Sertão e Litoral no Pensamento Social Brasileiro. Goiânia: Editora UFG.

TEIXEIRA, Pedro Ludovico (1973). Memórias. Goiânia: Livraria Editora Cultura Goiana.

UNES, Wolney (2001). Identidade art déco de Goiânia. São Paulo: Ateliê Editorial. Goiânia, Ed. Da UFG.

VASCONCELOS, Adirson (1978). A mudança da capital. Brasilia: Edição do autor. VIDAL, Laurent (2009). De Nova Lisboa a Brasília: a invenção de uma capital (séculos XIX-XX). Brasília: Editora Universidade de Brasília.

\section{Arquivos, acervos e coleções consultados}

Acervo da Biblioteca da Universidade Federal de Goiás

MONTEIRO, Ofélia Sócrates (1938). Como nasceu Goiânia. São Paulo: Empresa Gráfica da Revista dos Tribunais.

TEIXEIRA, Pedro Ludovico (1973). Memórias. Goiânia: Livraria Editora Cultura Goiana.

Arquivo da Casa de Altamiro de Moura Pacheco.

BOLETIM INFORMATIVO NO 5 . Esboço de um projeto de colonização no Estado de Goiás. CASALUCE, Giacinto (Org.) (1949). Goiânia: Imprensa Oficial do Estado. Arquivo Histórico Estadual de Goiás (IHGG) - Goiânia.

- Pasta dos Governadores ( no 2) Jerônimo Coimbra Bueno

Diário Oficial (15/07/1950)

Decreto no 49.873 de 11/01/1961 e Anexos (nº1- Súmula da Carta de 1939 ao Getúlio Vargas; no 2- Cruzada Rumo ao Oeste Discurso do Presidente Getúlio Vargas 
proferido no Automóvel Clube de Goiás e Manifesto para a organização da "Cruzada rumo ao Oeste"- no 3- Manifesto por uma civilização sertaneja- no 4- Relatório da Comissão Preliminar de Estudos da civilização sertaneja (1956) membro: Abelardo Coimbra Bueno.

BUENO, Jerônimo Coimbra (1961). A Fundação Coimbra Bueno pela nova capital do Brasil - Decreto no 49.873 de 11 de janeiro de 1961. Departamento de Imprensa Nacional.

Arquivo publico do Distrito Federal

BUENO, Abelardo Coimbra (1990). Depoimento - Programa de História Oral. Brasilia, Arquivo Publico do Distrito Federal - pág. 22. 